\title{
The B-chromosome polymorphism of the grasshopper Eyprepocnemis plorans in North Africa: II. Parasitic and neutralized $\mathrm{B}_{1}$ chromosomes
}

\author{
M Bakkali, F Perfectti and JPM Camacho \\ Departamento de Genética, Facultad de Ciencias, Universidad de Granada, 18071, Granada, Spain
}

\begin{abstract}
The transmission of the $B_{1}$ chromosome through females has been analysed in three Moroccan populations (Smir, SO.DE.A. and Mechra) of the grasshopper Eyprepocnemis plorans. We analysed transmission ratio $\left(k_{B}\right)$ variation at two levels: intra-individual (to test female age effects) and interindividual (to test for A chromosome effects). In $81.8 \%$ of females, $k_{B}$ did not differ among successive egg-pods, suggesting no effect of female age. The remaining females $(18.2 \%)$, showed significant differences in $k_{B}$ values among egg-pods, but without clear temporal patterns. In Smir, $k_{B}$
\end{abstract}

ranged between $B$ elimination (0.244) and B accumulation (0.689) but there was no net accumulation (mean \pm s.e. $=$ $0.463 \pm 0.045)$. In SO.DE.A., all females analysed transmitted $B_{1}$ at a Mendelian rate, with a mean $k_{B}$ equal to 0.512 \pm 0.020 . In Mechra, $k_{B}$ ranged from 0.341 to 0.972 , with mean $k_{B}(0.575 \pm 0.029)$ showing a net $B$ accumulation. All these observations suggest that the $B_{1}$ chromosome could be at a drive-suppression stage in Smir and Mechra, but that it has already been neutralised in SO.DE.A.

Heredity (2002) 88, 14-18. DOI: 10.1038/sj/hdy/6800002

Keywords: accumulation; arms race; B chromosome; coevolution; drive; grasshopper; Eyprepocnemis plorans; Orthoptera

\section{Introduction}

B chromosomes are large pieces of dispensable supernumerary DNA usually lacking functional genes, showing irregular modes of transmission and, in many cases, decreasing the fitness of individuals carrying them. In spite of being a frequent phenomenon (about 15\% of described living species have been estimated to carry them; Beukeboom, 1994) discovered long ago (Wilson, 1907), their origin and evolution is beginning to be understood only recently (for review, see Camacho et al, 2000).

Two classical hypotheses have been proposed to explain the maintenance of $B$ chromosomes in natural populations. The parasitic or selfish model (Östergren, 1945; Nur, 1966a, b; Nur, 1977; Jones, 1985; Shaw and Hewitt, 1990) proposes that B chromosomes maintain themselves by the action of accumulation mechanisms (eg, meiotic drive) that counterbalance their deleterious effects on host fitness. Most B chromosomes fit this model. The heterotic model (White, 1973), however, argues that B chromosomes lacking drive may be maintained because of their beneficial effects on the fitness of individuals carrying small number of Bs. Some B chromosomes are good candidates to be heterotic since they have an obvious beneficial effect on carrier fitness (eg, Nectria haematococca (Miao et al, 1991a, b) and Avena sativa (Dherawattana and Sadanaga, 1973)), but their population dynamics has been analysed only in Allium schoeno-

Correspondence: Dr M Bakkali, Departamento de Genética, Facultad de Ciencias, Universidad de Granada, 18071, Granada, Spain. E-mail: mbakkali@ugr.es

Received 16 October 2000; accepted 6 August 2001 prasum, where Bs lack drive and are beneficial in increasing viability from seed to seedling (Holmes and Bougourd, 1989; Plowman and Bougourd, 1994).

Camacho et al (1997) have proposed a long-term model for the evolution of parasitic B chromosomes, in which the establishment of a B chromosome depends on the existence of an accumulation mechanism facilitating the initial increase in B frequency, surpassing possible deleterious effects on host fitness. The B frequency increase provides the conditions for the selective spread of host genes leading to the suppression of $B$ drive and thus to the neutralisation of the B which, after a long stochastic decline, could be eliminated. The model finally suggests the possibility of regeneration of the polymorphism by the substitution of the neutralised $B$ variant by a newly arisen B variant showing accumulation. Under this model, the same B could show drive or not, depending on its evolutionary status at the moment of analysis. In addition, differences in drive could depend, at least theoretically, on the existence of cryptic variation (ie, not recognisable by cytological techniques) in the B chromosomes.

The study of the B chromosome polymorphism of the grasshopper Eyprepocnemis plorans in the Iberian Peninsula has shown all the stages of this life cycle, ie driving and neutralised Bs (Camacho et al, 1997; Zurita et al, 1998) as well as polymorphism regeneration (Zurita et al, 1998).

The B chromosome polymorphism has recently been found in Moroccan populations of E. plorans, with the most widespread B variant being similar, in C-banding (Bakkali et al, 1999) and FISH (Cabrero et al, 1999) patterns, to the most widespread $B$ variant in the Iberian Peninsula $\left(B_{1}\right)$. Research in the Iberian Peninsula 
(Henriques-Gil and Arana, 1990; López-León et al, 1992; Camacho et al, 1997; Zurita et al, 1998) has shown that $B_{1}$ has been neutralised and replaced by another variant $\left(B_{2}\right)$ in the Granada (where it has later been neutralised) and East-Málaga populations, and by $\mathrm{B}_{5}$ in Fuengirola (Málaga) (also neutralised). In addition, $B_{2}$ has recently been replaced by $\mathrm{B}_{24}$ in Torrox (Málaga).

Since the status of the E. plorans B polymorphism in Morocco is unknown, the purpose of this paper is to analyse $\mathrm{B}_{1}$ transmission through females (which is the driving sex in Iberian populations) from three Moroccan populations to ascertain its evolutionary status.

\section{Materials and methods}

We sampled three Moroccan populations of the grasshopper Eyprepocnemis plorans. In 1996, we collected 57 males and 34 females from Mechra (close to Mechra-belKsiri) and 44 males and 30 females from SO.DE.A. (near to Ksar-el-Kebir). In 1997, we caught 34 males and 32 females from Smir (between Ceuta and Tetouan). The three populations were located on a north-south transect, with $129 \mathrm{Km}$ from Smir to SO.DE.A. and $75 \mathrm{Km}$ from SO.DE.A. to Mechra (see map in Bakkali et al, 1999).

To perform controlled crosses, the number of B chromosomes in males can be detected in vivo by means of the technique described in López-León et al (1993), one that is not possible in females. For this reason, many useless crosses are inevitably set up in all transmission analyses. To minimise these, and since B chromosome frequency was relatively low in these populations (Bakkali et al, 1999), we artificially increased B chromosome frequency in each population by collectively crossing two-thirds of females with all males carrying $\mathrm{B}$ chromosomes (high B frequency, or $\mathrm{H}$ crosses). The remaining females were crossed to males lacking $B$ chromosomes (low B frequency, or L crosses). Grasshopper culture conditions were similar to those described in Herrera et al (1996).

Controlled crosses destined for the study of B chromosome transmission through females were performed by crossing, individually, $\mathrm{F}_{1} \mathrm{OB}$ males, from both $\mathrm{L}$ or $\mathrm{H}$ crosses, with virgin $\mathrm{F}_{1}$ females from $\mathrm{H}$ crosses. Eighty such crosses were performed in each population. All crosses involved a male and a female from the same population.

Egg pods were incubated at $28^{\circ} \mathrm{C}$ for 11 days before egg dissection and embryo fixation, as described by López-León et al (1993). Females were dissected after being anaesthetised with ethyl acetate vapour, and the ovaries were fixed in 3:1 ethanol-acetic acid. The cytological analysis of all fixed materials was performed by the techniques described in Camacho et al (1991) and LópezLeón et al (1992).

We calculated egg fertility as the proportion of eggs containing an embryo in an egg-pod. The B chromosome transmission ratio $\left(k_{B}\right)$ was calculated as the mean number of $\mathrm{B}$ chromosomes in the progeny divided by the total number of Bs in the parents (in the present case, divided by the number of Bs in the female parent, since all fathers lacked Bs). To compare $k_{B}$ with the expected Mendelian rate (0.5) we used the Z-test proposed by López-León et al (1992):

$$
Z=\frac{\left(k_{B}-0.5\right)}{\sqrt{\frac{0.25}{N}}}
$$

where $\mathrm{N}$ is the total number of embryos. $\mathrm{Z}$ values higher than +1.96 indicate $B$ accumulation, and $Z$ values lower than -1.96 indicate $B$ elimination.

Differences in $k_{B}$ among pods laid by the same female were tested by a contingency $\chi^{2}$ test performed with the $\mathrm{R} \times \mathrm{C}$ computer program, which employs the metropolis algorithm to obtain an unbiased estimate of the exact $P$ value (Raymond and Rousset, 1995). Twenty batches of 1000 simulated replicates were performed in all cases, and the sequential Bonferroni method was used to minimise type I errors.

The overall tendency for $k_{B}$ variation in each population was analysed by means of a one-group $t$-test, with an expected mean equal to 0.5. Nested ANOVA was performed to partition the $k_{B}$ variance into population and individual levels. One-way ANOVA was used to test for $B$ effects on egg fertility, and correlation analysis was performed to investigate possible relationship between $k_{B}$ and egg fertility.

\section{Results}

The transmission of the $B_{1}$ chromosome was analysed at two levels: among pods within females (intra-individual level) and among females within populations (inter-individual level). Thirty-eight out of 240 controlled crosses performed were informative for $B$ transmission (ie, involving females harbouring the $\mathrm{B}_{1}$ chromosome and yielding at least 25 analysable offspring): nine from Smir, six from SO.DE.A. and 23 from Mechra.

\section{Intra-individual level}

Several successive egg pods were analysed in 33 out of 38 controlled crosses. After applying the sequential Bonferroni method, four crosses from Smir $(44.44 \%$ of females from this population) and two from Mechra $(10.53 \%)$ showed significant differences in $B_{1}$ transmission among successive egg pods (Table 1). No cross in SO.DE.A. showed significant difference among successive egg pods. These temporal changes in $\mathrm{B}_{1}$ transmission ratio showed no consistent temporal pattern (Table 1), which, in addition to the fact that they were absent in most crosses $(81.8 \%)$, suggest that female age did not affect $B_{1}$ transmission ratio. The situation in Smir, however, needs further study since almost half of the crosses analysed showed temporal variation in $B_{1}$ transmission ratio.

\section{Inter-individual level}

One $(11.1 \%)$ out of the nine females carrying one or more $\mathrm{B}_{1}$ in Smir showed $\mathrm{B}_{1}$ accumulation $\left(k_{B}\right.$ significantly higher than 0.5$)$, three $(33.3 \%)$ showed $\mathrm{B}_{1}$ elimination $\left(k_{B}\right.$ significantly lower than 0.5), and the remaining five females $(55.6 \%)$ showed a near-Mendelian transmission $\left(k_{B}\right.$ not significantly different from 0.5$)$ (Table 2 ). In this population, $k_{B}$ was between 0.244 and 0.689 (mean \pm s.e. $=0.463 \pm 0.045$ ). In SO.DE.A., the six females analysed transmitted $B_{1}$ at a Mendelian ratio (Table 2), with a mean $k_{B}$ equal to $0.512 \pm 0.020$. In Mechra, seven out of 23 females analysed $(30.4 \%)$ showed $B_{1}$ accumulation, three 
Table $1 \mathrm{~B}_{1}$ transmission in six females where $k_{B}$ (transmission ratio of $\mathrm{B}_{1}$ ) varied between their pods. These females represented $18.2 \%$ of a total of 33 where more than one pod were analysed

\begin{tabular}{|c|c|c|c|c|c|c|c|c|c|c|c|c|c|}
\hline \multirow[t]{2}{*}{ Population } & \multirow[t]{2}{*}{$\begin{array}{l}\text { Cross } \\
\text { code }\end{array}$} & \multirow[t]{2}{*}{$\begin{array}{l}\text { Bs in } \\
\text { female }\end{array}$} & \multirow[t]{2}{*}{ Pod } & \multirow[t]{2}{*}{ Eggs } & \multirow[t]{2}{*}{ Embryos } & \multirow[t]{2}{*}{ Fertility } & \multicolumn{3}{|c|}{ Embryo offspring with } & \multirow[t]{2}{*}{$k_{B}$} & \multirow[t]{2}{*}{ Z } & \multicolumn{2}{|c|}{$\begin{array}{c}\text { Between-pod } \\
k_{B} \text { comparison }\end{array}$} \\
\hline & & & & & & & $O B$ & $1 B$ & $2 B$ & & & $x^{2}$ & $P$ \\
\hline \multirow{12}{*}{ Smir } & SM27 & 1 & 1 & 52 & 47 & 0.904 & 31 & 16 & 0 & 0.340 & -2.188 & & \\
\hline & & & 2 & 48 & 48 & 1.000 & 31 & 17 & 0 & 0.354 & -2.021 & & \\
\hline & & & 3 & 50 & 41 & 0.820 & 35 & 4 & 0 & 0.103 & -4.964 & & \\
\hline & & & 4 & 47 & 46 & 0.979 & 39 & 7 & 0 & 0.152 & -4.718 & 14.732 & 0.0021 \\
\hline & SM37 & 1 & 1 & 29 & 23 & 0.793 & 21 & 2 & 0 & 0.087 & -3.962 & & \\
\hline & & & 2 & 28 & 27 & 0.964 & 12 & 10 & 0 & 0.455 & -0.426 & & \\
\hline & & & 3 & 29 & 29 & 1.000 & 15 & 13 & 0 & 0.464 & -0.378 & 9.439 & 0.0095 \\
\hline & SM38 & 1 & 1 & 42 & 40 & 0.952 & 16 & 23 & 0 & 0.590 & 1.121 & & \\
\hline & & & 2 & 48 & 48 & 1.000 & 2 & 45 & 0 & 0.957 & 6.272 & & \\
\hline & & & 3 & 20 & 20 & 1.000 & 15 & 5 & 0 & 0.250 & -2.236 & 35.567 & 0.000 \\
\hline & SM75 & 2 & 1 & 30 & 28 & 0.933 & 18 & 10 & 0 & 0.179 & -3.402 & & \\
\hline & & & 2 & 42 & 41 & 0.976 & 5 & 31 & 2 & 0.461 & -0.487 & 17.777 & 0.0001 \\
\hline \multirow[t]{4}{*}{ Mechra } & M1 & 2 & 1 & 50 & 47 & 0.940 & 10 & 27 & 8 & 0.478 & -0.298 & & \\
\hline & & & 2 & 39 & 39 & 1.000 & 1 & 19 & 18 & 0.724 & 2.758 & 12.097 & 0.002 \\
\hline & M51 & 1 & 1 & 42 & 38 & 0.905 & 28 & 10 & 0 & 0.263 & -2.920 & & \\
\hline & & & 2 & 45 & 45 & 1.000 & 9 & 36 & 0 & 0.800 & 4.025 & 24.033 & 0.000 \\
\hline
\end{tabular}

(13.0\%) showed $\mathrm{B}_{1}$ elimination and the remaining 13 $(56.6 \%)$ showed a Mendelian ratio (Table 2$)$. Mean $k_{B}$ was $0.575 \pm 0.029(0.341-0.972)$.

As a whole, $k_{B}$ did not differ significantly from the Mendelian ratio in Smir (one-group t-test, with expected mean equal to $0.5, t_{8}=-0.825, P=0.433$ ) and SO.DE.A. $\left(t_{5}=0.629, P=0.557\right)$, but it indicated net accumulation in Mechra $\left(t_{22}=2.600, P=0.017\right)$.

A nested ANOVA partitioned total $k_{B}$ variance into population and individual levels (Table 3 ), showing significant differences among females within populations, but interpopulation differences did not reach significance.

There were no significant differences between the female $k_{B s}$ deduced from male and female embryo progeny in any of the populations analysed (Smir: $t_{8}=0.96$ and $P=0.37$; SO.DE.A: $t_{5}=1.17, P=0.30$; Mechra: $t_{22}=$ $0.31, P=0.76$ ). This suggests that $B_{1}$ does not cause any sex-dependent mortality during early embryogenesis.

Table 2 shows that 1B females from the three populations yielded a total of 10 embryo offspring with $2 \mathrm{~B}$, among the 2425 embryos they produced. Since all male parents were $0 \mathrm{~B}$, these embryos should be derived from non-disjunction of the $\mathrm{B}$ univalent during female meiosis. This phenomenon thus occurred only in $0.41 \%$ of meioses.

\section{Effects on egg fertility}

One-way ANOVA performed on all types of female (including $0 \mathrm{~B}$ ones) to compare egg fertility between $0 \mathrm{~B}$, $1 \mathrm{~B}$ and $2 \mathrm{~B}$ females, showed the absence of $\mathrm{B}$ effects in Smir $(\mathrm{F}=0.63, d f=2,32, P=0.54)$, SO.DE.A. $(\mathrm{F}=0.01$, $d f=1,30, P=0.92)$ and Mechra $(F=0.19, d f=2,52, P=$ $0.83)$. A correlation analysis between $k_{B}$ and egg fertility showed a significant negative correlation in Mechra $(r=$ -0. 445, $P=0.033)$ but not in Smir $(r=-0.126, P=0.746)$ or SO.DE.A. $(r=-0.122, P=0.817)$. The significance in Mechra, however, was removed by the application of the sequential Bonferroni test. In fact, it depended crucially on a single outlier cross whose elimination would give a non-significant correlation in the remaining crosses $(r=$ -0.078, $P=0.729$ ). Therefore, there was no obvious relationship between $B_{1}$ transmission and egg fertility.

\section{Discussion}

B chromosome transmission ratio has been shown to decrease with female age in the grasshopper Myrmeleotettix maculatus (Shaw and Hewitt, 1984). In Moroccan E. plorans, most crosses where several successive egg pods were analysed showed no variation in $k_{B}$. A minority of these crosses (most of them from the Smir population; see Table 1) showed significant differences in $k_{B}$ between pods, although with no obvious trend to increase or decrease with female age. This variation in $k_{B}$ could be due to factors related to the reproductive biology of $E$. plorans, which were not controlled in these experimental crosses. For instance, it has been shown that females get proteinaceous nutrients from male ejaculate, which they incorporate into the eggs they lay, thus increasing their rate of egg production (Pardo et al, 1995). In addition, Herrera et al (1996) reported male effects on female $k_{B}$. These observations suggest that factors such as the number of matings performed by a female before laying each egg pod or the number of days between mating and laying, could modify female reproductive conditions and change $k_{B}$ from pod to pod.

The variable transmission ratios observed between different females in the same population (significant female effect, see Table 3) could be explained by: (a) an effect of the genetic background in which Bs are transmitted and, presumably, a control of A chromosomes over B transmission; (b) cryptic B-chromosome variation responsible for $k_{B}$ variation; or (c) an unidentified environmental effect. Since the experimental crosses were performed in the laboratory under a controlled environment, explanation (c) is the least feasible. Since the presence of some type of A chromosome genetic control over B accumulation has been shown in several plant and animal 
Table 2 Transmission analysis of $B_{1}$ in each controlled cross performed with specimens from Smir (SM), SO.DE.A (SO) and Mechra (M). $k_{B}=\mathrm{B}_{1}$ transmission ratio

\begin{tabular}{|c|c|c|c|c|c|c|c|c|c|c|}
\hline \multirow[t]{2}{*}{ Cross } & \multirow{2}{*}{$\begin{array}{l}\text { Bs in } \\
\text { Female }\end{array}$} & \multirow[t]{2}{*}{ Pods } & \multirow[t]{2}{*}{ Eggs } & \multirow[t]{2}{*}{ Embryos } & \multirow[t]{2}{*}{ Fertility } & \multicolumn{3}{|c|}{ Embryo offspring with } & \multirow[t]{2}{*}{$k_{\mathrm{B}}$} & \multirow[t]{2}{*}{ Z } \\
\hline & & & & & & $O B$ & $1 B$ & $2 B$ & & \\
\hline $\mathrm{SM}_{7}$ & 1 & 4 & 142 & 90 & 0.634 & 47 & 40 & 0 & 0.460 & -0.750 \\
\hline $\mathrm{SM}_{27}$ & 1 & 4 & 197 & 182 & 0.924 & 136 & 44 & 0 & 0.244 & -6.857 \\
\hline $\mathrm{SM}_{29}$ & 1 & 6 & 194 & 145 & 0.747 & 63 & 72 & 0 & 0.533 & 0.775 \\
\hline $\mathrm{SM}_{37}$ & 1 & 3 & 86 & 79 & 0.919 & 48 & 25 & 0 & 0.342 & -2.692 \\
\hline $\mathrm{SM}_{38}$ & 1 & 3 & 110 & 108 & 0.982 & 33 & 73 & 0 & 0.689 & 3.885 \\
\hline $\mathrm{SM}_{43}$ & 1 & 3 & 98 & 77 & 0.786 & 41 & 34 & $2^{*}$ & 0.494 & -0.114 \\
\hline $\mathrm{SM}_{72}$ & 1 & 2 & 61 & 48 & 0.787 & 24 & 24 & 0 & 0.500 & 0 \\
\hline $\mathrm{SM}_{39}$ & 2 & 5 & 92 & 81 & 0.88 & 5 & 59 & 15 & 0.563 & 1.125 \\
\hline $\mathrm{SM}_{75}$ & 2 & 2 & 72 & 69 & 0.958 & 23 & 41 & 2 & 0.341 & -2.585 \\
\hline $\mathrm{SO}_{13}$ & 1 & 1 & 36 & 32 & 0.889 & 14 & 14 & 0 & 0.500 & 0 \\
\hline $\mathrm{SO}_{15}$ & 1 & 2 & 62 & 51 & 0.823 & 20 & 22 & $1^{*}$ & 0.558 & 0.762 \\
\hline $\mathrm{SO}_{38}$ & 1 & 3 & 95 & 82 & 0.863 & 42 & 34 & 0 & 0.447 & -0.918 \\
\hline $\mathrm{SO}_{47}$ & 1 & 5 & 223 & 211 & 0.946 & 88 & 115 & 0 & 0.567 & 1.895 \\
\hline $\mathrm{SO}_{57}$ & 1 & 3 & 90 & 78 & 0.867 & 39 & 31 & $1^{*}$ & 0.465 & -0.593 \\
\hline $\mathrm{SO}_{61}$ & 1 & 2 & 78 & 55 & 0.705 & 23 & 27 & 0 & 0.540 & 0.566 \\
\hline $\mathrm{M}_{9}$ & 1 & 1 & 39 & 37 & 0.949 & 17 & 18 & $2^{*}$ & 0.595 & 1.151 \\
\hline $\mathrm{M}_{11}$ & 1 & 2 & 59 & 59 & 1 & 35 & 23 & 0 & 0.397 & -1.576 \\
\hline $\mathrm{M}_{13}$ & 1 & 2 & 47 & 47 & 1 & 17 & 25 & 0 & 0.595 & 1.234 \\
\hline $\mathrm{M}_{19}$ & 1 & 2 & 58 & 57 & 0.983 & 26 & 31 & 0 & 0.544 & 0.662 \\
\hline $\mathrm{M}_{31}$ & 1 & 1 & 55 & 55 & 1 & 18 & 36 & $1^{*}$ & 0.691 & 2.832 \\
\hline $\mathrm{M}_{40}$ & 1 & 2 & 51 & 40 & 0.784 & 12 & 24 & 0 & 0.667 & 2.000 \\
\hline M41 & 1 & 3 & 84 & 76 & 0.905 & 27 & 49 & 0 & 0.645 & 2.524 \\
\hline $\mathrm{M}_{43}$ & 1 & 2 & 50 & 36 & 0.72 & 1 & 35 & 0 & 0.972 & 5.667 \\
\hline $\mathrm{M}_{48}$ & 1 & 5 & 153 & 135 & 0.882 & 87 & 45 & 0 & 0.341 & -3.656 \\
\hline $\mathrm{M}_{51}$ & 1 & 2 & 87 & 83 & 0.954 & 37 & 46 & 0 & 0.554 & 0.988 \\
\hline $\mathrm{M}_{55}$ & 1 & 3 & 48 & 46 & 0.958 & 27 & 19 & 0 & 0.413 & -1.180 \\
\hline $\mathrm{M}_{57}$ & 1 & 2 & 68 & 67 & 0.985 & 28 & 38 & 0 & 0.576 & 1.231 \\
\hline $\mathrm{M}_{61}$ & 1 & 2 & 88 & 88 & 1 & 29 & 58 & $1^{*}$ & 0.682 & 3.411 \\
\hline $\mathrm{M}_{64}$ & 1 & 3 & 95 & 92 & 0.968 & 58 & 34 & 0 & 0.370 & -2.502 \\
\hline $\mathrm{M}_{68}$ & 1 & 3 & 124 & 122 & 0.984 & 73 & 49 & 0 & 0.402 & -2.173 \\
\hline $\mathrm{M}_{71}$ & 1 & 3 & 93 & 85 & 0.914 & 44 & 38 & $1^{*}$ & 0.482 & -0.329 \\
\hline $\mathrm{M}_{74}$ & 1 & 2 & 74 & 70 & 0.946 & 35 & 34 & $1^{*}$ & 0.514 & 0.239 \\
\hline $\mathrm{M}_{78}$ & 1 & 2 & 73 & 70 & 0.959 & 22 & 47 & 0 & 0.681 & 3.010 \\
\hline $\mathrm{M}_{1}$ & 2 & 2 & 89 & 86 & 0.966 & 11 & 46 & 26 & 0.590 & 1.646 \\
\hline $\mathrm{M}_{7}$ & 2 & 1 & 58 & 50 & 0.862 & 10 & 19 & 18 & 0.585 & 1.167 \\
\hline $\mathrm{M}_{46}$ & 2 & 2 & 97 & 92 & 0.948 & 0 & 58 & 32 & 0.678 & 3.373 \\
\hline $\mathrm{M}_{70}$ & 2 & 2 & 32 & 32 & 1 & 0 & 23 & 9 & 0.641 & 1.591 \\
\hline $\mathrm{M}_{79}$ & 2 & 1 & 32 & 27 & 0.844 & 2 & 16 & 8 & 0.615 & 1.177 \\
\hline
\end{tabular}

*Resulting from B-chromosome non-disjunction.

Table 3 Nested ANOVA partitioning total $k_{B}$ variance into three levels: among populations, among females within populations and among egg-pods within females (error)

\begin{tabular}{lrccc}
\hline & $d f$ & $M S$ & $F$ & $P$ \\
\hline Among populations & 2 & 0.121 & 3.17 & 0.054 \\
Among females & 34 & 0.039 & 1.71 & 0.038 \\
Error & 54 & 0.023 & & \\
\hline
\end{tabular}

species, including E. plorans (for review, see Camacho et al, 2000) we regard this possibility as the most plausible. Under this hypothesis, in Moroccan E. plorans populations, the A control over B transmission have been completed in SO.DE.A., where all females analysed showed $k_{B}$ close to the Mendelian one. In Mechra, however, the A control seems to be in an earlier evolutionary stage since $B_{1}$ still accumulated in seven females (30.4\%). In Smir, the A control was stronger since there was $B_{1}$ accumulation in a single female.
The observed differences in $k_{B}$ among populations indicate that the $\mathrm{B}_{1}$ polymorphism is at different evolutionary stages in these localities. The B seems to be near-neutral in SO.DE.A., it is almost neutralised in Smir, but is still selfish in Mechra. The demonstration that $\mathrm{B}_{1}$ (the original $\mathrm{B}$ chromosome in E. plorans from Iberian and Moroccan populations) shows accumulation in Mechra, but not in the other two populations, confirms the existence of different evolutionary stages for a same B in different populations. Under the long-term evolution model (Camacho et al, 1997), the $B_{1}$ polymorphism in Morocco would be younger in the most southern population, Mechra, where $B_{1}$ still drives, and older in the two other populations where it is closer to neutralisation. In fact, in the three populations studied in this work, $k_{B}$ values are roughly ordered in a north-south gradient, with the lowest value in the northern population (Smir, 0.463), an intermediate value at SO.DE.A. (0.512), and the highest $k_{B}$ at the southern population (Mechra, 0.575). This gradient would coincide with an age gradient, with the B polymorphism being older in northern populations and younger in 
southern populations. This would suggest a possible north-south invasion of the B in Morocco, and thus gives support to the hypothesis of the north Mediterranean origin of this B polymorphism (Bakkali et al, 1999).

One of the most widespread deleterious effects of parasitic B chromosomes is a decrease in host fertility (for review, see Jones and Rees, 1982). In E. plorans, the only significant effect of B chromosomes on host fitness was a decrease in egg fertility detected in Torrox for a selfish $\mathrm{B}\left(\mathrm{B}_{24}\right)$ that had recently invaded the population to substitute a neutralised $B\left(B_{2}\right)$ (Zurita et al, 1998). This effect, however, is not apparent in neutralised Bs as, for instance, $B_{2}$ (Camacho et al, 1997), but it can be forced to be manifest by limiting the number of female matings (Muñoz et al, 1998). This could suggest that deleterious effects of parasitic B chromosomes may disappear in parallel to drive neutralisation. The absence of obvious effects of the $B_{1}$ chromosome on egg fertility in all three Moroccan populations analysed in the present paper could indicate either a high tolerance to B chromosomes in these environments or an increase in tolerance that has evolved in parallel to the drive neutralisation. The introduction of B chromosomes and the analysis of egg fertility in Moroccan populations lacking B chromosomes, if they actually exist, could help to clear this point.

\section{Acknowledgements}

M Bakkali wishes to thank the 'Agencia Española De Cooperación Internacional, Instituto de Cooperación con el Mundo Arabe, Mediterráneo y Paises en Vias de Desarrollo' (Spain) and the 'Ministère de l'Enseignement Supérieur, de la Formation des Cadres et de la Recherche Scientifique' (Morocco) for conceding a studentship, and Mr Soulaïmane Bakkali for his help in capturing specimens. This study was partially supported by grants from the Spanish 'Ministerio de Ciencia y Tecnología' (no. BOS2000-1521) and 'Plan Andaluz de Investigación, Grupo no. CVI-165'.

\section{References}

Bakkali M, Cabrero J, López-León MD, Perfectti F, Camacho JPM (1999). The B chromosome polymorphism of the grasshopper Eyprepocnemis plorans in North Africa: I.B variants and frequency. Heredity 83: 428-434.

Beukeboom LW (1994). Bewildering Bs: an impression of the 1st B-Chromosome Conference. Heredity 73: 328-336.

Cabrero J, López-León MD, Bakkali M, Camacho JPM (1999). Common origin of B chromosome variants in the grasshopper Eyprepocnemis plorans. Heredity 83: 435-439.

Camacho JPM, Cabrero J, Viseras E, López-León MD, Navas Castillo J (1991). G-banding in two species of grasshoppers and its relationship to $\mathrm{C}, \mathrm{N}$ and fluorescence banding techniques. Genome 34: 638-643.

Camacho JPM, Shaw MW, López-León MD, Pardo MC, Cabrero J (1997). Population dynamics of a selfish B chromosome neutralized by the standard genome in the grasshopper Eyprepocnemis plorans. Am Nat 149: 1030-1050.

Camacho JPM, Sharbel TF, Beukeboom LW (2000). B chromosome evolution. Phil Trans R Soc Lond B 355: 163-178.
Dherawattana A, Sadanaga K (1973). Cytogenetics of a crown rust-resistant hexaploid oat with $42+2$ fragment chromosomes. Crop Sci 13: 591-594.

Henriques-Gil N, Arana P (1990). Origin and substitution of B chromosomes in the grasshopper Eyprepocnemis plorans. Evolution 44: 747-753.

Herrera JA, López-León MD, Cabrero J, Shaw MW, Camacho JPM (1996). Evidence for B chromosome drive suppression in the grasshopper Eyprepocnemis plorans. Heredity 76: 633-639.

Holmes DS, Bougourd SM (1989). B-chromosome selection in Allium schoenoprasum II. Natural populations. Heredity 63: $83-87$.

Jones RN (1985). Are B chromosomes selfish? In: Cavalier-Smith T (ed). The Evolution of Genome Size, Wiley: London, pp 397425.

Jones RN, Rees H (1982). B chromosomes. Academic Press: New York.

López-León MD, Cabrero J, Camacho JPM, Cano MI, Santos JL (1992). A widespread B chromosome polymorphism maintained without apparent drive. Evolution 46: 529-539.

López-León MD, Cabrero J, Pardo MC, Viseras E, Camacho JPM, Santos JL (1993). Generating high variability of B chromosomes in the grasshopper Eyprepocnemis plorans. Heredity 71: 352-362.

Miao VP, Covert SF, Vanetten HD (1991a). A fungal gene for antibiotic resistance on a dispensable (B) chromosome. Science 254: 1773-1776.

Miao VP, Matthews DE, Vanetten HD (1991b). Identification and chromosomal location of a family of cytochrome P-450 genes for pisatin detoxification in the fungus Nectria heamatococca. Mol Gen Genet 226: 214-223.

Muñoz E, Perfectti F, Martín-Alganza A, Camacho JPM (1998). Parallel effect of a B chromosome and a mite decreasing female fitness in the grasshopper Eyprepocnemis plorans. Proc $R$ Soc Lond Ser B 265: 1903-1909.

Nur U (1996a). Harmful B chromosomes in a mealy bug population. Genetics 54: 1225-1238.

Nur U (1966b). The effect of supernumerary chromosomes on the development of mealy bugs. Genetics 54: 1239-1249.

Nur U (1977). Maintenance of a "parasitic" B chromosome in the grasshopper Melanoplus femur-rubrum. Genetics 87: 499512 .

Östergren G (1945). Parasitic nature of extra fragment chromosomes. Bot Notiser 2: 157-163.

Pardo MC, López-León MD, Hewitt GM, Camacho JPM (1995). Female fitness is increased by frequent mating in grasshoppers. Heredity 74: 654-660.

Plowman AB, Bougourd SM (1994). Selectively advantageous effects of B chromosomes on germination behavior in Allium schoenoprasum L. Heredity 72: 587-593.

Raymond ML, Rousset F (1995). An exact test for population differentiation. Evolution 49: 1280-1283.

Shaw MW, Hewitt GM (1984). The effect of temperature on meiotic transmission rates of the B chromosome of Myrmeleotettix maculatus (Orthoptera: Acrididae). Heredity 53: 259-268.

Shaw MW, Hewitt GM (1990). B chromosomes, selfish DNA and theoretical models: where next? In: Futuyma D, Antonovics J (eds). Oxford Surveys in Evolutionary Biology, vol. 7, pp 197223.

White MJD (1973). Animal Cytology and Evolution. 3rd edn. Cambridge University Press: London.

Wilson EB (1907). The supernumerary chromosomes of Hemiptera. Science 26: 870-871.

Zurita S, Cabrero J, López-León MD, Camacho JPM (1998). Polymorphism regeneration for a neutralized selfish B chromosome. Evolution 52: 274-277. 